\title{
https://doi.org/10.46813/2021-134-138 \\ DISSIPATIVE INSTABILITIES AND SUPERRADIATION REGIMES (CLASSIC MODELS)
}

\author{
V.M. Kuklin, E.V. Poklonskiy \\ V.N. Karazin Kharkiv National University, Kharkiv, Ukraine \\ E-mail:v.m.kuklin@karazin.ua; evpoklonsky@karazin.ua
}

\begin{abstract}
The generation of an electromagnetic field by oscillators in an open resonator is discussed in a one-dimensional approximation. In this case, the development of the so-called dissipative instability - the dissipative generation regime. Such an instability with the generation of electromagnetic oscillations arises when the decrement of oscillations in an open resonator in the absence of oscillators turns out to be greater than the increment of the resulting instability of the system of oscillators placed in this resonator. It is assumed that the oscillators do not interact with each other, and only the resonator field affects their behavior. If the resonator field is absent or small, the superradiance regime is possible, when the radiation of each oscillator is essential and the field in the system is the sum of all the eigenfields of the oscillators. In the dissipative regime of instability generation, the system of oscillators is synchronized by the induced resonator field. The synchronization of the oscillators in the superradiance mode owes its existence to the integral field of the entire system of oscillators. With a weak nonlinearity of the oscillators, a small initiating external field is required to excite the generation regime. It is noteworthy that the maximum value of the superradiance field is approximately two times less than the maximum field that the same particles could generate if they were at the same point. In all cases, for a given open resonator, the superradiance field turned out to be somewhat larger than the resonator field. Nevertheless, for the same resonator, the increments and attainable field amplitudes in both cases are of the same order of magnitude.
\end{abstract}

PACS: 05.45.Xt, 52.40.Mj

\section{INTRODUCTION}

Interest in the dynamics of dissipative instabilities, that is, the processes of generation or amplification of oscillations under conditions of significant absorption of their energy (or the extraction of energy due to radiation from the core) was due to practical necessity. In electronics, attention was drawn to the peculiarity of these processes in works [1 - 3]. Later it was shown that dissipative processes in these regimes do not lead to the appearance of an instability threshold $[4,5]$ when practically monoenergetic electron beams (of high quality [6]) are used for generation. In this case, the greatest energy flux from the system to the loss channel can be achieved [7]. In such open systems, when the reflection of waves from the boundaries of the system is weakened, dissipative generation regimes and superradiance regimes [ 8 - 12] can be realized, the physical mechanisms of which were discussed in $[13,14]$.

The peculiarity of the superradiance regime is that a resonator or waveguide field may not be present in the system of oscillators. As a rule, superradiance regimes are realized in open systems with weak reflection (or even its absence) of excited oscillations from the ends of the system (resonator or waveguide). Then the direct interaction of oscillators becomes the main physical phenomenon. In the classical case, the oscillators have an energy that significantly exceeds the energy of the field quantum. Long-term interaction of such oscillators (which only gradually lose their energy) with the total field of the system can lead to mutual synchronization of the phase of an individual oscillator and the phase of this total field. In this case, induced radiation is formed even in the absence of a resonator or waveguide field. Remarkable is the similarity between the superradiance process and the dissipative instability regime, discovered by the authors of [16] under the conditions of the existence of a resonator or waveguide field.
The aim of this work is to consider the features of dissipative instabilities and superradiance regimes for systems of excited classical oscillators; comparison of the characteristic times of these processes, as well as the attainable amplitudes of the excited fields.

\section{RADIATION OF CLASSICAL OSCILLATORS}

The issues of oscillator radiation in electronic devices have been actively discussed since [17, 18]. An important circumstance is the conditions for synchronization by the eigenfields of the radiation of the system of oscillators in the superradiance regime. It turns out that only when the nonlinearity of the oscillators is taken into account, it becomes possible in this case to ensure the phase synchronization of the field and the oscillator [19] (see also [20]).

Consider an oscillator whose charge (electron) moves along the OX axis, that is $x(t)=i \cdot a \cdot \exp \{-i \omega t+i \psi\}, \quad$ at the same time, $\operatorname{Re} x=a \cdot \sin (\omega t-\psi)$ where $\vec{r}=\left(x(t), 0, z_{0}\right)$. In this case, the speed $d x / d t=a \cdot \omega \cdot \exp \{-i \omega t+i \psi\}$ and current $J_{x}=-e d x / d t=-e \cdot a \cdot \omega \cdot \exp \{-i \omega t+i \psi\}$ can be written as the equation describing the field excitation by the oscillator current takes the form

$$
\begin{aligned}
& \frac{\partial^{2} E_{x}}{\partial z^{2}}-\frac{1}{c^{2}} \frac{\partial^{2} D_{x}}{\partial t^{2}}=\frac{4 \pi}{c^{2}} \frac{\partial J_{x}}{\partial t}= \\
& =\frac{4 \pi}{c^{2}} \cdot e \cdot a \cdot \omega^{2} \cdot i \cdot \exp \{-i \omega t+i \psi\} \cdot \delta\left(z-z_{0}\right) .
\end{aligned}
$$

The dielectric constant of the medium in the absence of oscillators is set equal to unity $\left(\varepsilon_{0}=1\right)$. We are looking for a solution for the amplitude of the electric field in the form $\vec{E}=(E \cdot \exp \{-i \omega t+i k z\}, 0,0)$, that is 
$E_{x}=E \cdot \exp \{-i \omega t+i k z\}$, assuming the slowness of the change in the complex amplitude $E_{x}(t, z)$ :

$$
\begin{aligned}
& \left|\frac{1}{E_{x}(t, z)} \frac{\partial}{\partial t} E_{x}(t, z)\right|<<\omega, \\
& \left|\frac{1}{E_{x}(t, z)} \frac{\partial}{\partial z} E_{x}(t, z)\right|<<k .
\end{aligned}
$$

The field excited in the system of oscillators consists of the general field of the resonator and the sum of all fields of the individual oscillators.

\section{FIELD OF THE WAVEGUIDE OR RESONATOR}

However, a resonator or a waveguide can shape the field in such a way that the form of the field does not depend on the radiation of individual oscillators, or, more precisely, it is not essential to take into account individual fields of the oscillators. This is the traditional so-called resonator (waveguide) mode of radiation. Note that such a field, generally speaking, should consist of traveling waves in two directions $(k>0)$

$$
E_{x}=E_{+} \cdot \exp \{-i \omega t+i k z\}+E_{-} \cdot \exp \{-i \omega t-i k z\},
$$

where the slowly varying complex wave amplitude has the form $E_{ \pm}=\left|E_{ \pm}\right| \cdot \exp \left\{i \varphi_{ \pm}\right\}$. The equation describing the interaction of oscillators with these fields can be represented as

$$
\begin{aligned}
& 2 i \omega\left(\frac{\partial E_{ \pm}}{\partial t}+\delta_{D}\right)= \\
& =-e \omega^{2} \frac{4 \pi n_{0}}{N \cdot 2 i} \int a_{s} d z \cdot \exp \left\{i \psi_{s} \mp i k z\right\} \cdot \delta\left(z-z_{s}\right),
\end{aligned}
$$

where $\delta_{D}$ is the decrement of wave absorption in the absence of sources, $A_{j}=a_{j} \exp \left(i \psi_{j}\right)$. We represent the equations of motion in the form

$$
\frac{d}{d t} \frac{v_{i}}{\sqrt{1-\frac{\left|v_{i}\right|^{2}}{c^{2}}}}+\omega^{2} x_{i}=-\frac{e}{m} E_{x}\left(z_{i}, t\right)
$$

where

$$
\begin{aligned}
& x_{i}(t)=i \cdot a_{i} \cdot \exp \{-i \omega t+i \psi\}=i A \cdot \exp \{-i \omega t\}, \\
& v_{i}=\omega \cdot a_{i} \cdot \exp \{-i \omega t+i \psi\}=\omega A \cdot \exp \{-i \omega t\} .
\end{aligned}
$$

We use the following notation below $\frac{e|E(t)| \exp \{i \varphi\}}{m \gamma_{0} \omega a_{0}}=\mathrm{E}(t), \quad \gamma_{0} t=\tau, \quad \gamma_{0}^{2}=\pi e^{2} n_{0} / m=\omega_{p e}^{2} / 4$, $\mathrm{A}_{j}=a_{j} / a_{0}, k_{0} z_{j}=2 \pi Z_{j}, \theta=\delta / \gamma_{0}, \alpha=\frac{3 \omega}{4 \gamma_{0}}\left(k_{0} a_{0}\right)^{2}-$ determines the dependence of the relativistic particle mass on the velocity. We rewrite (4) and (5) in the form

$$
\begin{aligned}
& \frac{\partial}{\partial \tau} \mathrm{E}_{ \pm}+\theta \cdot \mathrm{E}_{ \pm}=\frac{1}{N} \sum_{j=1}^{N} \mathrm{~A}_{j} \cdot \exp i\left\{\mp 2 \pi Z_{j}\right\}, \\
& \frac{d}{d \tau} \mathrm{A}_{j}-i \alpha \mathrm{A}_{j}^{3}=-\frac{1}{2}\left[\mathrm{E}_{+} \cdot \exp i\left\{2 \pi Z_{j}\right\}+\right. \\
& \left.+\mathrm{E}_{-} \cdot \exp i\left\{-2 \pi Z_{j}\right\}\right],
\end{aligned}
$$

imagine $\Delta_{j}=\alpha A_{j}^{2}$.

The law of conservation of energy can be obtained in the form

$$
\left(\frac{\partial}{\partial \tau}+2 \theta\right)\left\{\left|\mathrm{E}_{+}\right|^{2}+\left|\mathrm{E}_{-}\right|^{2}\right\}=2 \frac{\partial}{\partial \tau} \sum_{j=1}^{N}\left|\mathrm{~A}_{j}\right|^{2}
$$

\section{DESCRIPTION OF THE DISSIPATIVE INSTABILITY REGIME}

Let us consider below the so-called dissipative regime of instability. If there is no preferred direction of radiation, at a sufficiently large value of radiation losses $\delta_{D}>\partial E / E \partial t$, the decrement of which can be determined from the condition

$$
\delta_{D}=\left(\int_{S} c<E>^{2} / 4 \pi\right) \cdot d S / \int_{V}\left(<E>^{2} / 4 \pi\right) \cdot d V \approx c / l .
$$

Equation (6) then takes the form

$$
\mathrm{E}_{ \pm}=\frac{1}{N \theta} \sum_{j=1}^{N} \mathrm{~A}_{j} \cdot \exp i\left\{\mp 2 \pi Z_{j}\right\},
$$

and the equation of motion (7) does not change, but can be represented as follows

$$
\begin{aligned}
& \frac{d}{d \tau} \mathrm{A}_{j}-i \alpha \mathrm{A}_{j}\left|\mathrm{~A}_{j}\right|^{2}= \\
& -\frac{1}{2} \mathrm{E}\left(Z_{j}\right)=-\frac{1}{N} \sum_{i=1}^{N} \mathrm{~A}_{i} \operatorname{Cos}\left\{2 \pi\left(Z_{j}-Z_{i}\right\},\right.
\end{aligned}
$$

where the equation for the field can be written in the form

$$
\begin{aligned}
& \mathrm{E}\left(Z_{j}\right)=\mathrm{E}_{+} \cdot \exp i\left\{2 \pi Z_{j}\right\}+\mathrm{E}_{-} \cdot \exp i\left\{-2 \pi Z_{j}\right\}= \\
& =\frac{2}{N \theta} \sum_{i=1}^{N} \mathrm{~A}_{i} \operatorname{Cos}\left\{2 \pi\left(Z_{j}-Z_{i}\right\} .\right.
\end{aligned}
$$

The energy conservation law in this case takes the form

$$
\sum_{j=1}^{N} \frac{d\left|\mathrm{~A}_{j}\right|^{2}}{d \tau}=-\operatorname{Re} \sum_{j=1}^{N} \mathrm{E}\left(Z_{j}\right) \mathrm{A}_{j}^{*} .
$$

In this case $\left\{\left|\mathrm{E}_{+}\right|^{2}+\left|\mathrm{E}_{-}\right|^{2}\right\}=-\operatorname{Re} \sum_{j=1}^{N} \mathrm{E}\left(Z_{j}\right) \mathrm{A}_{j}^{*}$.

The field $\mathrm{E}\left(Z_{j}\right)$ here is the field of the induced radiation. It is not difficult to see the nature of the formation of particle radiation coherence under the action of a waveguide or resonator field. Neglecting the relativistic corrections, the equation for the phase of the oscillator can be written in the form

$$
\begin{aligned}
& \partial \psi_{s} / \partial t=-\left(e|E| / m \omega a_{0}\right) \cdot \operatorname{Sin}\left(\varphi-\psi_{s}\right)= \\
& =-(\Omega / n) \cdot \operatorname{Sin}\left(\varphi-\psi_{s}\right),
\end{aligned}
$$

where $e a_{0}|E| \omega / m \omega^{2} a_{0}^{2}=2 d|E| / n \hbar=\Omega / n$ is the energy of the oscillator, expressed by the number of field quanta. For oscillators in the quantum case $n=1$ and $\Omega$ is the Rabi frequency.

Obviously, the matching time - synchronizing the phase of the oscillator with the phase of the field at the place where the particle is located is of the order of $n / \Omega$ almost the same for all oscillators in the core. Recall that the reciprocal of the Rabi frequency $\Omega^{-1}$ in quantum mechanics is proportional to the probability of induced radiation [21, 22].

If we go to the time scale $\tau=\gamma_{0} t \rightarrow \gamma t=\gamma_{0}^{2} d / c=\gamma_{0} / \theta$, then the variables will have the form $\frac{e|E(t)| \exp \{i \varphi\}}{m \gamma \omega_{0} a_{0}}=\mathrm{E}(t), \quad \gamma t=\tau, \quad \gamma^{2}=\pi e^{2} M / m c$, $\mathrm{A}_{j}=a_{j} / a_{0}, \quad k_{0} z_{j}=2 \pi Z_{j}, \quad \alpha=\frac{3 \omega_{0}}{4 \gamma}\left(k_{0} a_{0}\right)^{2}, \quad$ and the dissipative excitation mode takes the form

$$
\begin{aligned}
& \frac{d}{d \tau} \mathrm{A}_{j}-i \alpha\left(\mathrm{A}_{j}\left|\mathrm{~A}_{j}\right|^{2}\right)=-\frac{1}{2} \mathrm{E}\left(Z_{j}\right) \\
& =-\frac{1}{N} \sum_{i=1}^{N} \mathrm{~A}_{i} \operatorname{Cos}\left\{2 \pi\left(Z_{j}-Z_{i}\right\}\right.
\end{aligned}
$$


and the field satisfies the expression

$$
\begin{aligned}
& \mathrm{E}(\mathrm{Z})=\left[\mathrm{E}_{+} \cdot \exp i\{2 \pi Z\}+\mathrm{E}_{-} \cdot \exp i\{-2 \pi Z\}\right]= \\
& =\frac{2}{N} \sum_{i=1}^{N} \mathrm{~A}_{i} \operatorname{Cos}\left\{2 \pi\left(Z-Z_{i}\right)\right\} .
\end{aligned}
$$

Here the time scale is somewhat different $\tau_{1}=\gamma t$; the increment has also changed, $n_{0}-$ the density of particles per unit volume, $M=b \cdot n_{0}, b$ - the length of the considered space in the longitudinal direction. The energy conservation law takes the form

$$
\sum_{j=1}^{N} \frac{d\left|\mathrm{~A}_{j}\right|^{2}}{d \tau}=-\operatorname{Re} \sum_{j=1}^{N} \mathrm{E}\left(Z_{j}\right) \mathrm{A}_{j}{ }_{j}
$$

to the summation $\mathrm{j}$ over the core space.

\section{DESCRIPTION OF THE SUPERRADIATION MODE. TOTAL FIELD OF OSCILLATORS}

Let us consider the superradiance regime when the resonator field or waveguide field is absent. It is also possible to determine the total radiation field of the oscillators in the same volume. First, let's find the field of one oscillator. For the amplitude of the radiation field slowly varying in space, the equation is valid

$$
\begin{aligned}
& \frac{\partial E}{\partial z}=2 e a \omega^{2} \frac{\pi}{c^{2} k} \cdot \exp \{i \psi+i k z\} \cdot \delta\left(z-z_{0}\right)= \\
& =\lambda \cdot \delta\left(z-z_{0}\right) .
\end{aligned}
$$

The solution of which $E=C+\lambda \cdot \theta\left(z-z_{0}\right)$, where $\theta(\mathrm{z}<0)=0, \theta(\mathrm{z} \geq 0)=1$. Since for the wave emitted by the oscillator the equation $D(\omega, k) \equiv\left(\omega^{2} \varepsilon_{0}-k^{2}\right)=0$ is valid, the roots of which $k_{1,2}= \pm\left(\omega_{0} \operatorname{Re} \varepsilon_{0} / c\right)\left(1+i \operatorname{Im} \varepsilon_{0} / \operatorname{Re} \varepsilon_{0}\right) \approx \pm\left(\omega_{0} / c \varepsilon_{0}\right)(1+i 0)$, then for the wave propagating in the direction $z>z_{0}$, the wavenumber $k=k_{1}>0$ and the value of the constant $C$ should be chosen equal to zero, in order to avoid unlimited growth of the field at infinity. For a wave propagating in the direction $z<z_{0}$ of the wavenumber $k=k_{2}<0$, the value of the constant should be chosen equal $-\lambda$ for the same reasons. The amplitude of the electric field in this case

$$
E_{x}=2 \pi e a \omega_{0} M \cdot c^{-1} \exp \{-i \omega t+i \psi\} \cdot \exp \left\{i k\left|z-z_{0}\right|\right\},
$$

because

$$
\begin{aligned}
& \exp \left\{i k\left(z-z_{0}\right)\right\} \cdot \theta\left(z-z_{0}\right)+ \\
& \exp \left\{-i k\left(z-z_{0}\right)\right\} \cdot \theta\left(z_{0}-z\right)=\exp \left\{i k\left|z-z_{0}\right|\right\} .
\end{aligned}
$$

For one particle in such a volume of unit cross section and length of the resonator, it is numerically equal to unity.

The equation of motion for an oscillating electron has the form (5). Using these notation, we write (5) taking into account (18) in form

$$
\begin{aligned}
& \frac{d A_{j}}{d t}-i \frac{\left|3 A_{j}\right|^{2} \cdot \omega^{3}}{4 c^{2}} A_{j}= \\
& -\frac{\pi \cdot e^{2} \cdot M}{m c} \cdot \frac{1}{N} \sum_{s=1}^{N} A_{s} \exp \left\{i k\left|z_{j}-z_{s}\right|\right\},
\end{aligned}
$$

$$
\begin{aligned}
& \frac{d A_{j}}{d t}-i \frac{\left|3 A_{j}\right|^{2} \cdot \omega^{3}}{4 c^{2}} A_{j}= \\
& -\frac{\pi \cdot e^{2} \cdot M}{m c} \cdot \frac{1}{N} \sum_{s=1}^{N} A_{s} \exp \left\{i k\left|z_{j}-z_{s}\right|\right\},
\end{aligned}
$$

or in dimensionless form

$$
\begin{aligned}
& \frac{d \mathrm{~A}_{j}}{d \tau}-i \Delta_{j} \mathrm{~A}_{j}= \\
& -\frac{1}{N} \sum_{s=1}^{N} \mathrm{~A}_{s} \cdot \exp \left\{i 2 \pi\left|Z_{j}-Z_{s}\right|\right\}- \\
& -\mathrm{E}_{0} \cdot e^{2 \pi i Z_{j}}=-\frac{1}{2} \mathrm{E}_{x}\left(Z_{j}, \tau\right)-\mathrm{E}_{0} \cdot e^{2 \pi i Z_{j}} .
\end{aligned}
$$

Here $\quad \gamma=\gamma_{0}^{2} / \delta_{D}=\pi e^{2} M / m c ; \quad \mathrm{E}=e E / m \omega \gamma a_{0} ;$ $\mathrm{A}=A / a_{0} ; \quad k_{0} z=2 \pi Z ; \quad \tau=\gamma t ; \quad \Delta_{j}=\alpha\left(\left|A_{j}\right|^{2} A_{j}\right) ;$ $\gamma_{0}^{2}=\pi e^{2} n_{0} / m=\omega_{p e}^{2} / 4 ; \alpha=3 k_{0}^{2} a_{0}^{2} \omega / 4 \gamma$.

The electric field strength of the oscillator radiation in dimensionless units can be described as follows

$$
\mathrm{E}_{x}(Z, \tau)=\frac{2}{N} \sum_{s=1}^{N} \mathrm{~A}_{s} \exp \left\{i 2 \pi\left|Z-Z_{s}\right|\right\} .
$$

in this case, the expression for the energy conservation law is the same as (16)

$$
\frac{d}{d \tau}\left|\mathrm{A}_{j}\right|^{2}=-\operatorname{Re}\left\{\mathrm{E}_{x}\left(Z_{j}, \tau\right) \mathrm{A}_{j}^{*}\right\} .
$$

\section{RESULTS OF NUMERICAL CALCULATIONS OF GENERATION MODELS}

\subsection{RESULTS OF CALCULATIONS WITHOUT TAKING INTO ACCOUNT THE EIGENFIELDS OF OSCILLATORS (14), (15), THAT IS, EXCLUD- ING EQUATIONS (20), (21)}

Such parameters were chosen for the calculation. The number of particles $N=3600, \alpha=1$. At the initial moment, the modules of the amplitudes of the oscillators are equal to unity $\left|\mathrm{A}_{j}(0)\right|=1$, the phases $\psi_{j}$ have random values in the range $(-\pi, \pi)$. Fig. 1 shows the time dependence of the modulus of the waveguide field at the edges of the system $(Z=0$ and $Z=1)$ and the maximum value of the modulus of the field in the system. Fig. 2 shows the dependence of the mean square of the oscillator amplitudes $|\mathrm{A}|_{e v}^{2}=\frac{1}{N} \sum_{j}\left|\mathrm{~A}_{j}\right|^{2}$ (average energy of the oscillators) on time.

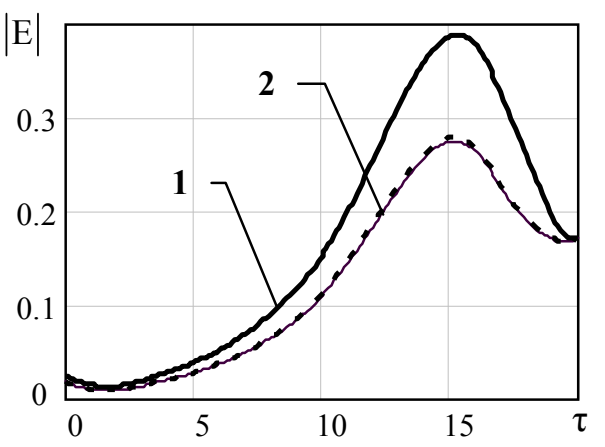

Fig. 1. Dependence of the field modulus in different parts of the system on time $\tau$ :

$1-\max |\mathrm{E}| ; 2-|\mathrm{E}(\mathrm{Z}=1)|=|\mathrm{E}(\mathrm{Z}=0)|$ 


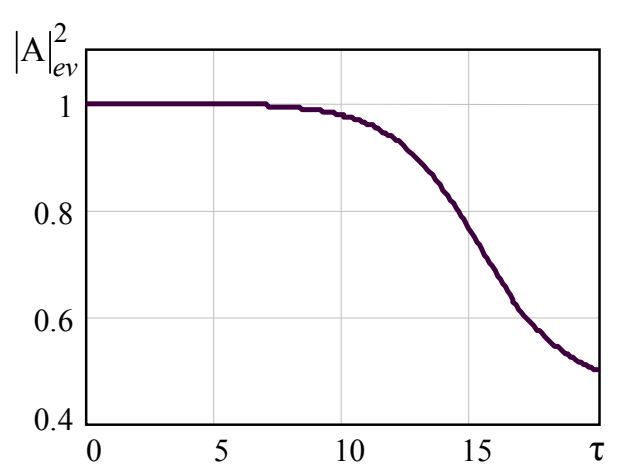

Fig. 2. Time dependence of the mean square of the oscillator amplitudes $|\mathrm{A}|_{\text {ev }}^{2}$

During the development of the field, there is a partial synchronization of the phases of the oscillators with the phase of the field at the point where the oscillator is located. This is most clearly manifested at the moment of reaching the maximum of the field in the regions of the system where the field is greatest.

The field maximum is reached at the moment $\tau=15.2$. Fig. 3 shows the dependence of the field modulus along the length of the system at this moment. Fig. 4 shows the spatial distribution of the phase difference between the oscillators and the field $\Delta \psi_{j}=\arg \left(A_{j}\right)-\arg \left(E\left(Z_{j}\right)\right)=\psi_{j}-\varphi\left(Z_{j}\right)$ at this moment $(E(Z, \tau)=|E(Z, \tau)| \exp (\varphi(Z, \tau)))$.

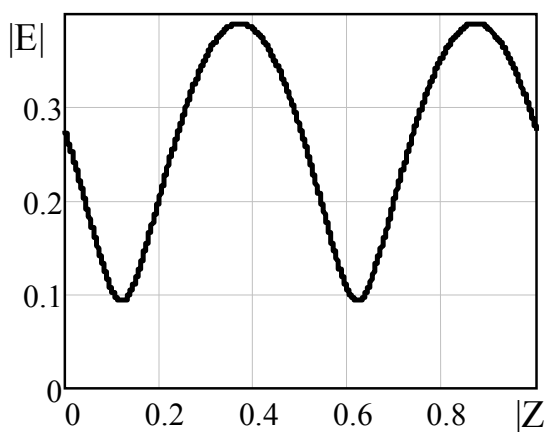

Fig. 3. Dependence of the field modulus on $Z$ at $\tau=15.2$

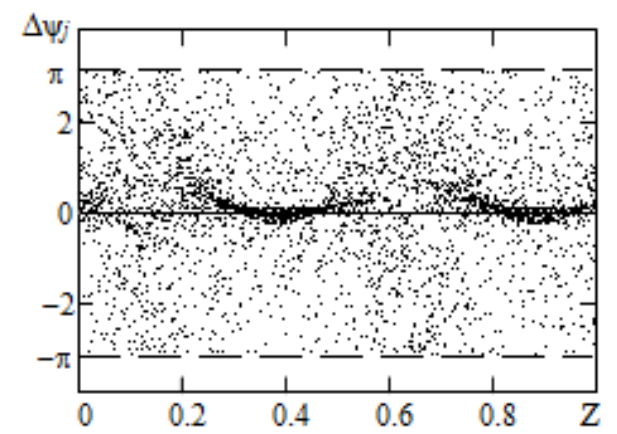

Fig. 4. Spatial distribution of the phase difference between the oscillator and the field for each particle at $\tau=15.2$

\subsection{RESULTS OF CALCULATIONS WITHOUT TAKING INTO ACCOUNT THE RESONATOR OR WAVEGUIDE FIELDS}

The following options are selected. The number of particles $N=3600, \alpha=1$. At the initial moment, the modules of the amplitudes of the oscillators are equal to unity $\left|\mathrm{A}_{j}(0)\right|=1$, the phases $\psi_{j}$ have random values in the range $(-\pi, \pi)$. For the selected value $\alpha=1$, no additional external field was used to initiate the superradiance process. However, it is important to note that the need for it arises at small $\alpha$, that is, weak nonlinearity. Fig. 5 shows the time dependence of the field modulus of the oscillators at the edges of the system $(Z=0$ and $Z=1)$ and the maximum value of the field modulus in the system. Fig. 6 shows the time dependence of the mean square of the oscillator amplitudes (average energy of the oscillators).

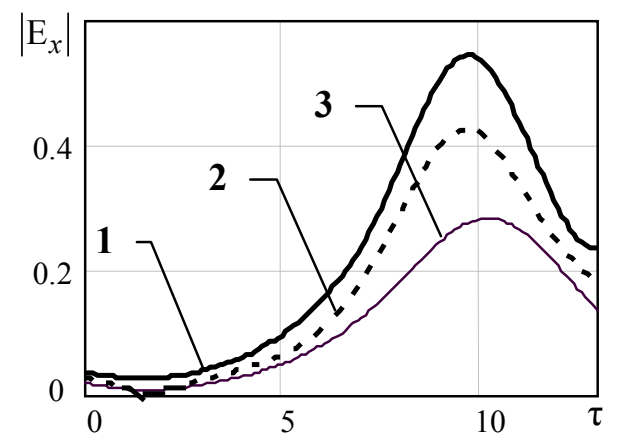

Fig. 5. Dependence of the field modulus in different parts of the system on time $\tau: 1-\max \left|\mathrm{E}_{x}\right|$;

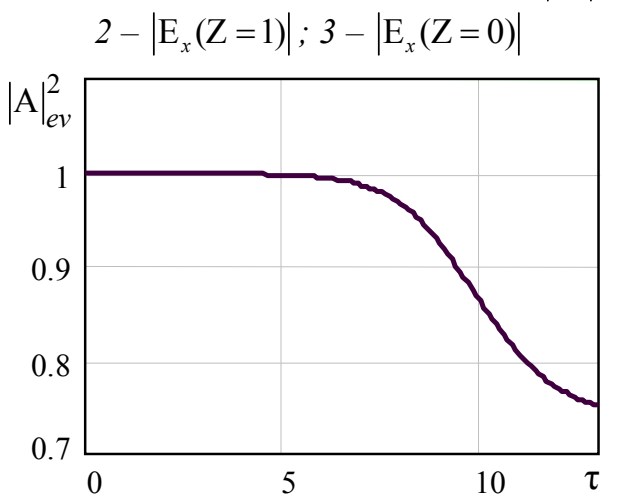

Fig. 6. Time dependence of the mean square of the oscillator amplitudes $|\mathrm{A}|_{e v}^{2}(\tau)$

The field maximum $\mathrm{E}_{x M A X}=0.54$ is reached at the moment $\tau=9$.7. The maximum possible with full coherence of radiation in the adopted units is equal $\left|\mathrm{E}_{x}\right|^{2}=1$, but in reality the level of coherence did not exceed $\left|\mathrm{E}_{x M A X}\right|^{2}(\alpha=1) \approx 0.27$ that is, $27 \%$. At lower values of nonlinearity there was $\left|\mathrm{E}_{x M A X}\right|^{2}(\alpha=0.2) \approx 0.4^{2}=0.16$, but an additional external field initiating the superradiance process was use $\mathrm{E}_{0}=0.05$.

Figs. 7 and 8 show the spatial distribution of the amplitudes of the oscillators $\left|\mathrm{A}_{j}\right|$ and the phase difference between the oscillators and the field $\Delta \psi_{j}=\arg \left(A_{j}\right)-\arg \left(E\left(Z_{j}\right)\right)=\psi_{j}-\varphi\left(Z_{j}\right)$ at the moment of the maximum field.

In the superradiance regime and with the previously considered dissipative instability, the effective decrement (responsible for radiation from the system) is quite significant, so the condition $\delta_{D}>\partial E / E \partial t$ is always satisfied. It should be noted that in equations (6) the instability increment $\gamma=\gamma_{0}^{2} / \delta_{D}=\left(\frac{\pi e^{2} n_{0}}{m}\right)\left(\frac{d}{c}\right)$, the 
nondissipative instability increment $\gamma_{0}$ for the system of oscillators is equal to half the Langmuir frequency $\gamma_{0} \approx \omega_{p e} / 2=\sqrt{\pi e^{2} n_{0} / m}$.

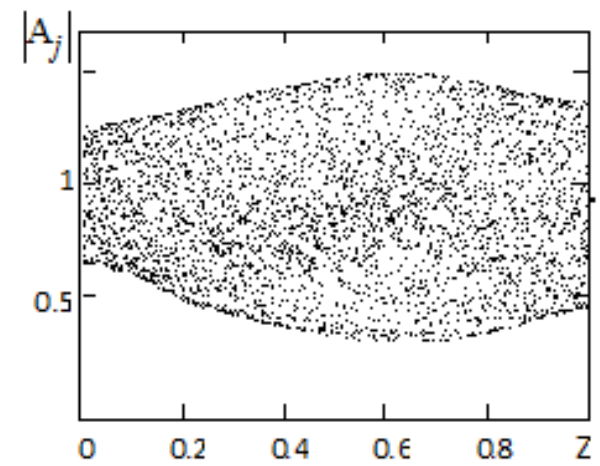

Fig. 7. Space distribution of oscillator amplitudes $\left|\mathrm{A}_{j}\right|$ at $\tau=9.7$

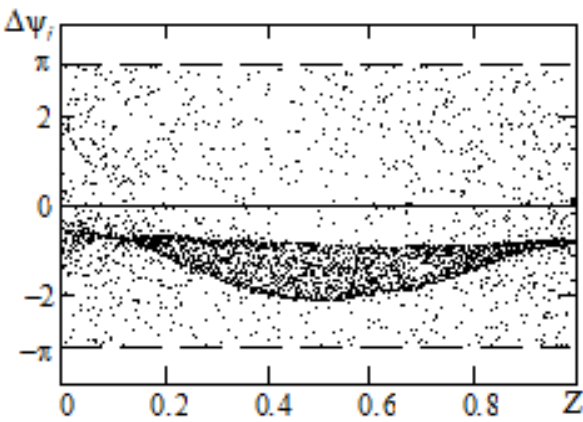

Fig. 8. Space distribution of the phase difference between the oscillator and the field at $\tau=9.7$

Dimensionless value of the electric field strength $\mathrm{E}=e E / m \omega_{0} a_{0} \gamma=e E / m \omega_{0} a_{0} \gamma_{0} \cdot\left(\delta_{D} / \gamma_{0}\right) \propto \delta_{D}$. That is, the real value of the intensity will be proportional to the square of the effective damping decrement.

$$
N=<\mathrm{E}>^{2} / 4 \pi \hbar \omega \propto\left(\frac{\delta_{D}}{\gamma_{0}}\right)^{2} .
$$

It is of interest to compare the excited field with a field of another type that could generate the same particles (shown in Figs. 9 and 10 by the dotted line). It is curious that in all cases the superradiance field would turn out to be greater than the resonator field.

One should also pay attention to the fact that the maximum value of the superradiance field is approximately two times less than the maximum field that the same particles could generate if they were located at one point (see Fig. 10). That is, the degree of coherence of superradiance is approximately equal to and slightly more than $25 \%$ (compare with [15]).

The growth of the field in the superradiance regime occurs from the level of fluctuations (i.e., from the level of spontaneous emission), the intensity of which is proportional to $1 / \sqrt{N}$, where $N$ is the number of particles. Under real conditions, the initial spontaneous field intensity in the superradiance regime is large and very low (under the conditions considered, it is 15 times less than the attainable amplitudes in the case of dissipative instability and in superradiance regimes).

In the example above $N=3600$, the spontaneous emission of particles is also very significant. Only with weak relativism $\alpha<<1$, to ensure generation, it is necessary to use an external initiating field.

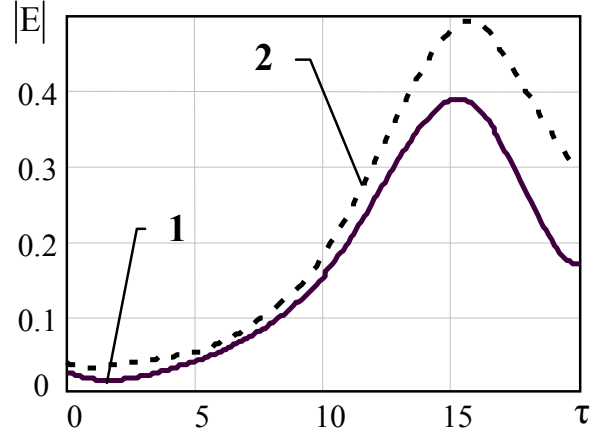

Fig. 9. Time dependence of the maximum amplitude of the resonator field (15) in the volume (solid line 1) and estimate of the total field (21), which could generate the same particles (dashed line 2). Here $\alpha=1$

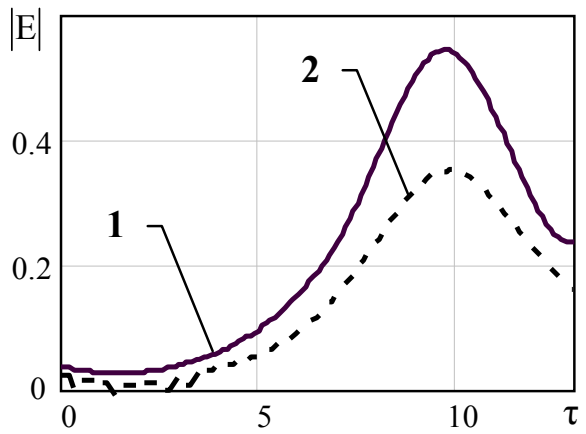

Fig. 10. Time dependence of the maximum amplitude of the superradiance field (21) in the volume (solid line 1) and an estimate of the resonator field (15), which could generate the same particles (dotted line 2). Here $\alpha=1$

In systems where the number of particles is very large (gas at normal pressure and a solid), the intensity of spontaneous emission is much lower than the required intensity of the induced generation field, therefore, to accelerate the process of synchronization of emitters, it is necessary to use an initiating field.

\section{ACKNOWLEDGEMENTS}

Authors grateful to V.A. Buts for useful remarks and attention to work.

\section{REFERENCES}

1. R.J. Briggs Electron-stream interaction with plasmas. Cambridge MIT Press, 1964.

2. B.B. Kadomtsev, A.B. Mikhailovsky, A.V. Timofeev. Waves of negative energy in dispersive media // ZhETF. 1964, v. 47, № 6, p. 2266-2268.

3. V.U. Abramovich, V.I. Shevchenko. To the nonlinear theory of dissipative instability of a relativistic beam in plasma // ZhETF. 1972, v. 62, № 4, p. 1386-1391.

4. A.I. Akhiezer, I.A. Akhiezer, R.V. Polovin, A.G. Sitenko, K.N. Stepanov. Electrodynamics of plasma. M.: "Nauka", 1974, 720 p.

5. A.N. Kondratenko, V.M. Kuklin. Fundamentals of Plasma Electronics. M.: "Energoatomizdat", 1988, $320 \mathrm{p}$.

6. Ya.B. Fainberg. Plasma electronics // Ukr. physical zhurn. 1978, v. 23, № 11, p. 1885-1901.

7. A.N. Kondratenko, V.M. Kuklin, V.I. Tkachenko. Nonlinear theory of beam instability in collisional plasma // Izv. "Universities. Radiofizika". 1978, v. 21, № 10, p. 1535-1537. 
8. A.G. Zagorodniy, P.I. Fomin, A.P. Fomina. Superradiance of electrons in a magnetic field and a nonrelativistic gyrotron // Dop. NAS of Ukraine. 2004, № 4, p. 75-80.

9. L.I. Menshikov. Superradiance and related phenomena // Physics Uspekhi. 1999, v. 169, № 2, p. 113-154.

10. I.P. Gabitov, V.E. Zakharov, A.V. Mikhailov. Nonlinear theory of superfluorescence // ZhETF. 1984, v. 86, p. 1204-1216.

11. A.V. Andreev, V.I. Emelyanov, Yu.A. Il'inskiy. Collective spontaneous radiation (Dicke radiation) // Phys. 131, № 4, p. 655-694.

12. V.V. Zheleznyakov, V.V. Kocharovsky. Polarization waves and superradiance in active media // UFN. 1989, v. 159, № 2, p. 193-260.

13. R.H. Dicke. Coherence in Spontaneous Radiation Processes // Physical Review. 1954, v. 93, № 1, p. 99-110.

14. A.A. Andronov. On the issue of attenuation and growth of plasma waves // Izv. Universities. Radiophysics. 1961, v. 4, № 5, p. 861-866 (in Russian).

15. Ch.H. Townes. Production of Coherent Radiation by Atoms and Molecules // Spectrum. 1965, v. 2 (2), p. 30.

16. A.G. Zagorodny, V.M. Kuklin. Features of radiation in nonequilibrium media. in the book. Problems of theoretical physics. Scientific works / V.A. Buts et al; edit. V.M. Kuklin. Kh.: "KhNU", 2014, issue 1, p. 13-82 (in Russian).

17. A.V. Gaponov. Instability of a system of excited oscillators with respect to electromagnetic excitations // ZhETP. 1960, v. 39, № 2, p. 326-321.

18. A.V. Gaponov, M.I. Petelin, V.K. Yulpatov. Induced emission of excited classical oscillators and its use in high-frequency electronics // Izv. "Universities. Radiophysics”, 1967, v. 10, № 9-10, p. 1414-1433.

19. Yu.A. Il'inskii, N.S. Maslova. Classical analog of superradiance in a system of interactingnonlinear oscillators // Zh. Eksp. Teor. Fiz. 1988. v. 91, № 1, p. 171-174.

20. V.M. Kuklin, D.N. Litvinov, V.E. Sporov. Superradiance of stationary oscillators // Problems of Atomic Science and Technology. Series "Plasma Electronics and New Methods of Acceleration”. 2018, № 4, p. 217-220.

21. A.S. Davydov. Quantum Mechanics. M.: "Fizmatgiz". 1963, 748 p. (in Russian).

22. L. Allen, J. Eberly. Optical rfsonance and two-level atoms. Witey-lnterscicitce Publication John Witty and Sons. New York-London-Sydney-Toronto, 1975, 222 p.

Article received 07.06.2021

\section{ДИССИПАТИВНЫЕ НЕУСТОЙЧИВОСТИ И РЕЖИМЫ СВЕРХИЗЛУЧЕНИЯ (КЛАССИЧЕСКИЕ МОДЕЛИ) \\ В.М. Куклин, Е.В. Поклонский}

Обсуждается в одномерном приближении генерация электромагнитного поля осцилляторами, которые находятся в открытом резонаторе. В этом случае возможно развитие так называемой диссипативной неустойчивости - диссипативного режима генерации. Такая неустойчивость с генерацией электромагнитных колебаний возникает в случае, когда декремент колебаний в открытом резонаторе в отсутствие осцилляторов оказывается больше инкремента возникающей неустойчивости системы осцилляторов, помещенной в этот резонатор. Предполагается, что осцилляторы при этом между собой не взаимодействуют, и на их поведение влияет только резонаторное поле. Если же резонаторное поле отсутствует или невелико, возможен режим сверхизлучения, когда существенно излучение каждого осциллятора и поле в системе представляет собой сумму всех собственных полей осцилляторов. В диссипативном режиме генерации неустойчивости систему осцилляторов синхронизует индуцированное резонаторное поле. Синхронизация осцилляторов в режиме сверхизлучения обязана своим существованием интегральному полю всей системы осцилляторов. При слабой нелинейности осцилляторов для возбуждения режима генерации необходимо небольшое инициирующее внешнее поле. Примечательно, что максимальное значение поля сверхизлучения примерно в два раза меньше максимального поля, которое могли бы генерировать эти же частицы, если бы они находились в одной точке. Во всех случаях для данного открытого резонатора поле сверхизлучения оказалось несколько большим, чем резонаторное поле. Тем не менее, для одного и того же резонатора инкременты и достижимые амплитуды поля в обоих случаях одного порядка.

\section{ДИСИПАТИВНІ НЕСТІЙКОСТІ ТА РЕЖИМИ НАДВИПРОМІНЮВАННЯ (КЛАСИЧНІ МОДЕЛІ) \\ В.М. Куклін, С.В. Поклонський}

Обговорюється в одновимірному наближенні генерація електромагнітного поля осциляторами, які знаходяться у відкритому резонаторі. У цьому випадку можливий розвиток так званої дисипативної нестійкості дисипативного режиму генерації. Така нестійкість з генерацією електромагнітних коливань виникає в разі, коли декремент коливань у відкритому резонаторі у відсутності осциляторів виявляється більше інкременту виникаючої нестійкості системи осциляторів, вміщеній в цей резонатор. Передбачається, що осцилятори при цьому між собою не взаємодіють, і на їх поведінку впливає тільки резонаторне поле. Якщо ж резонаторне поле відсутнє або невелике, можливий режим надвипромінювання, коли істотне випромінювання кожного осцилятора і поле в системі є сумою всіх власних полів осциляторів. У дисипативному режимі генерації нестійкості систему осциляторів синхронізує індуковане резонаторне поле. Синхронізація осциляторів у режимі надвипромінювання зобов'язана своїм існуванням інтегральному полю всієї системи осциляторів. При слабкій нелінійності осциляторів для збудження режиму генерації необхідне невелике ініціалізуюче зовнішнє поле. Важливо, що максимальне значення поля надвипромінювання приблизно в два рази менше максимального поля, яке могли б генерувати ці ж частинки, якби вони знаходилися в одній точці. У всіх випадках для даного відкритого резонатора поле надвипромінювання виявилося трохи більшим, ніж резонаторне поле. Проте для одного і того ж резонатора інкременти і досяжні амплітуди поля в обох випадках одного порядку. 